\title{
Editorial
}

The first issue of Thorax was published 32 years ago. Until recently, the journal was owned by the British Medical Association but its contents and editorial policy were controlled by the Thoracic Society. From the beginning of this year, as a result of a new agreement, Thorax will be owned jointly by the British Medical Association and the Thoracic Society.

We hope that our readers will take pleasure in the newly designed cover, the first change in external appearance since the journal's inception. Our changes are not limited to the outward appearance of Thorax. The Editorial Board has been enlarged to achieve or augment representation in many specialist branches of thoracic medicine and surgery although the editors will also continue to appoint other prominent experts to assess the work of contributors.

Beginning with this issue, we shall publish regular editorials on topical or controversial subjects. We hope that these will disentangle matters of confusion, question strongholds of dogmatism, and sometimes express an individual and eccentric point of view. Thorax will also publish correspondence concerning our original contributions and will print authors' replies to comments on and criticism of their work. A lively correspondence column adds spice to the meat proffered by the original papers and, we hope, will stimulate further discussion. On page 10 is the first of a series of articles on the historical aspects of chest medicine. We should like to think that these will have a particular appeal to our younger readers, who might wish to acquire a sense of historical perspective in relation to the study of chest disease.

Until now it has been necessary to reject a high proportion of the isolated case reports submitted to us, solely because of lack of space. Many of these deserve publication, either because the condition has not previously been described, or because they reveal an unusual pattern of behaviour in an otherwise well-known disease. We hope to publish a larger selection of these case reports by offering to authors the alternative of publication as 'short reports' limited to 600 words. Details appear on the inside front cover.

Thorax publishes original work in every field of chest medicine and the related basic sciences. A review of the subjects covered in recent years has shown a deficiency of papers on anaesthesia, microbiology, radiology, and industrial medicine. We should like to encourage original work in these important specialties. Contributions on these subjects will be welcomed and given special consideration.

Thorax has always maintained a high standard in the content of its original contributions and in the quality and number of its radiographs and photomicrographs. The editors will continue to follow the ideals of excellence established by their predecessors and in these respects Thorax has not changed.

BENJAMIN B. MILSTEIN ANTHONY SEATON

\section{Asthma-contrasts in care}

It may be estimated that at any time approximately $2 \%$ of the population are suffering from asthma, and that in Britain two in every thousand asthmatics die of the disease each year. Asthma afflicts people of all ages and, while it is easily recognised in young non-smokers, it is frequently misdiagnosed as bronchitis or emphysema among the elderly. It is a frequent experience for chest physicians to see patients who have been disabled by years of breathlessness and yet whose whole life may be improved dramatically by simple treatment. Even when asthma has been correctly diagnosed, it is still commonplace to see the patient treated with old, often potentially addictive, barbiturate-containing drugs without attempts to monitor their efficacy and in a haphazard and arbitrary manner. Patients are still warned not to overuse their aerosol bronchodilators but are given no advice on what to do if these become ineffective. Severe exacerbations of the disease are frequently treated with a change of bronchodilator rather than by the introduction of the necessary corticosteroids.

Any doctor working in an asthma clinic is quickly impressed by the number of misconceptions in the minds of his colleagues about the 